\title{
Sharing Knowledge and Tools for Decision Support in
}

\section{Biomedicine and Healthcare}

\author{
John Mantas ${ }^{1}$, Arie Hasman ${ }^{2}$ and Jana Zvárová ${ }^{3}$ \\ ${ }^{1}$ University of Athens, Greece \\ 2 University of Amsterdam, The Netherlands \\ ${ }^{3}$ Charles University in Prague, The Czech Republic
}

The special topic conference Data and Knowledge for Medical Decision Support was held in Prague, April 17-19, 2013 under the auspices of the European Federation of Medical Informatics (EFMI). The EFMI conference focused on the important topic of how advanced information and communication technologies can be used to combine expert knowledge with best practices in the diagnosis, treatment and prevention of diseases. After review of all submissions a scientific program could be established with 49 lectures, 32 posters, 7 workshops and one panel. The conference was attended by more than 160 delegates from 31 countries. Selected papers of the EFMI conference were published by IOS Press [1].

One of the workshops titled Sharing Knowledge and Tools for Decision Support in Biomedicine and Healthcare was held at the 1st Faculty of Medicine of the Charles University in Prague on April 16, 2013. During the workshop 25 Ph.D. students from Charles University in Prague, Masaryk University in Brno, Technical University in Prague and several universities from other European countries presented their work. The workshop was chaired by Prof. John Mantas (University of Athens, Greece), Prof. Arie Hasman (University of Amsterdam, The Netherlands) and Prof. Jana
Zvárová (Charles University in Prague, The Czech Republic). Discussions about the presented lectures were at an international level with active involvement of both the chairs and participants. This created an added value for the Ph.D. students.

Based on their presentations during the workshop a number of students wrote full papers. These papers were submitted to different biomedical journals and ten of them to the European Journal for Biomedical Informatics (EJBI), listed among peer-reviewed journals published in the Czech Republic and approved by the Board of Government. The third issue of EJBI publishes in the year 2013 six full papers after a peer-review. We sincerely hope that the active participation at the workshop and the further comments of reviewers about the full papers highly contributed to the students' knowledge for a successful further development of their Ph.D. theses.

\section{Reference}

[1] Arie Hasman, Bernd Blobel, Jana Zvárová (eds): Data and Knowledge for Medical Decision Support. IOS Press, Amsterdam 2013 